\title{
Breathing CORONA into the PSYCHE: An Interesting Case Series During COVID-19 Pandemic
}

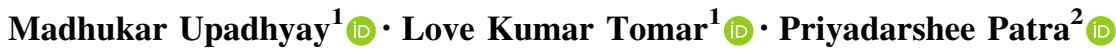

Received: 1 September 2020/Accepted: 7 October 2020/Published online: 15 October 2020

(C) Association of Otolaryngologists of India 2020

\begin{abstract}
The ongoing COVID 19 pandemic has taken a toll on not only physical health but the mental well being of the individuals too. This novel virus has shaken the very fabric of the society. Every individual irrespective of his education and socioeconomic status has been affected by this pandemic. It is surprising to see how the effects of this pandemic slowly crept into the psyche of the individuals thereby unleashing symptoms which were hidden till now. This series highlights few such cases where the presenting symptoms were initially thought to be ENT disorders but later revealed themselves as severe psychiatric symptoms in disguise. It is pertinent to note that timely intervention helped these individuals to recover completely and go back to leading a normal life in spite of prevailing uncertainty about the pandemic.
\end{abstract}

Keywords ENT $\cdot$ Psychiatry $\cdot$ Covid-19 $\cdot$ Novel symptoms

\section{Introduction}

The COVID-19 has affected the whole world at an unprecedented scale and has affected almost every aspect of human life. On one hand it is proving hazardous to

Madhukar Upadhyay

madhuwinsoscar@gmail.com

Love Kumar Tomar

happy5485@gmail.com

Priyadarshee Patra

priyadarshee.patra@gmail.com

158 Base Hospital, Siliguri, West Bengal 734014, India

2 Command Hospital, Kolkata, Kolkata, West Bengal 700001, India physical health while on other it is being detrimental to our mental health [1-4]. Current legislative and administrative measures like lockdown and work from home have severely affected the mental state of normal otherwise healthy individuals [5]. There has been a significant rise in stress levels of individuals leading to undue worries, anxiety and affective symptoms. Both the consequences of viral outbreak and imposed measures leading to social isolation along with restriction of activities in all domains of life have put the vulnerable individual to the risk of development of syndromal psychopathology [6]. Though most of the outpatient departments are having less number of patients than usual however Psychiatry OPD on the contrary continues to have regular visits of old and new psychiatric cases with novel symptoms ascribing to the COVID-19 pandemic [7]. Here we present a case series compiled at a peripheral hospital of individuals who initially presented to ENT OPD but were subsequently found to be in the need of psychiatric care and treatment. All the individuals in these case series were tested negative for COVID-19 by RT-PCR.

\section{Case 1}

A16 year old boy, studying in tenth standard brought by parents to ENT OPD with history of persistent coughing and making repeated sounds from the throat for the last 1 month. A detailed ENT evaluation including videolaryngoscopy failed to reveal any significant findings. However during the examination, the individual had to clear his throat multiple times despite the advice not to do so. In view of his persistent symptoms for which no ENT cause was found a psychiatric referral was made. Detailed history from the patient and his parents revealed that he was 
observed to be gargling excessively with saline water for the last 1 month since his area was declared Red zone during the pandemic. Gradually he started repeatedly coughing and making throat clearing sounds without any pain or difficulty in his throat. His symptoms were observed by his family members and he was advised to control this behavior as he offered no throat complaints on enquiring. However he was not able to suppress his behavior. He had no full control over them but would sometimes be able to suppress them. The abnormal sounds occurred everyday, sometimes several times a day. He could predict their occurrence but unable to tell what brings them up. No history of fever, loss of consciousness, heat or cold intolerance, tremors, any other abnormal movements of body parts or any repeated behavior. No history of any prescribed drug intake or psychoactive substance use. Mental state examination revealed there were no thought disorders, compulsive acts or cognitive deficits. However simple vocal tics like coughing and throat clearing were present. They were sudden, rapid, non-rhythmic, stereotypic and appear to be involuntary. They lasted between 30 and $60 \mathrm{~s}$. He was conscious and accessible during each episode. Physical examination including the central nervous system was normal. Laboratory tests, including complete blood count, erythrocyte sedimentation rate, liver function tests, kidney function tests, thyroid function tests, urine analysis, were all normal. A contrast-enhanced computed tomography scan of the brain was also normal. He was diagnosed as a case of Tic disorder unspecified and managed with habit reversal therapy, relaxation training and SDA Tab Aripiprazole $(10 \mathrm{mg})$. He gradually responded to the interventions and his tics abated within 8 weeks of treatment.

\section{Case 2}

A 28 years old female, a known case of allergic rhinitis, on topical steroid therapy came to ENT OPD with the specific history that her bouts of sneezing have increased since she came back from her hometown (a Red zone for COVID-19 pandemic) around 4 months back. There was no other supporting history or any clinical finding suggestive of a COVID-19 infection. Diagnostic nasal endoscopy was consistent with features of allergic rhinitis. However her husband told that she was noncompliant with her medications and worrying a lot for the past few days. Hence she was referred for psychiatric consultation. In Psychiatry OPD, she reported that she stopped taking her topical nasal steroid since the beginning of COVID 19 pandemic as she read on the internet that steroid use reduces immunity making a person vulnerable for infection. Gradually she developed a firm belief that she was immunosupressed and the Corona virus had 'entered into her body'. With worsening of nasal symptoms after discontinuation of treatment her belief further got reinforced. Her distress further worsened (persistent worries, sleep disturbance, excessive Google browsing to know about symptoms and cure of Corona infection) for which she was repeatedly counseled by family members but her belief did not change. She ordered various online commercial products and Ayurvedic medicines to improve her immunity. She had difficulty in pursuing the activity of daily living due to preoccupation with the belief. She was a non smoker with a negative history for drug or alcohol abuse and on no other concomitant medication. Physical examination and laboratory tests were normal. Mental state examination revealed hypochondriacal delusion of infestation with no other delusion or perceptual anomalies in clear sensorium with poor insight and disturbed biodrives. Psychometry revealed a high BPRS score (68). She was diagnosed and managed as a case of Delusional disorder-Delusional Infestation with SDA (Tab Risperidone), insight oriented psychotherapy and CBT. She was started on a combination of steroid and antihistamine topical nasal spray for her allergic rhinitis. Gradually over the next 6 weeks she had a favourable response to treatment with encapsulation of her delusion and improvement in her functioning.

\section{Case 3}

A 15 years old female, studying in ninth standard, belonging to middle socioeconomic status and resident of a semi urban area presented to ENT OPD along with her mother with complaints of excessive distress on wearing a mask as required for Covid precaution. As no local pathology was found, the ENT surgeon then referred her for psychiatric consultation. History revealed that for the last 3 months her school was closed and she was confined to home during lock down, now as the lockdown eased she wanted to venture out of the house. But she was unable to tolerate a face mask as she would develop abrupt intense anxiety and a feeling of suffocation. Symptoms were relieved within minutes of taking off the mask. After a few attempts over 7-8 days she was so distressed that she confined herself in the house, not venturing out even for a few minutes. Although she believed that fear was grossly excessive and irrational but expressed inability to control this fear and the consequent avoidance. She had cordial relations with family members and her friends. No history of any other phobia, free floating anxiety or persistence mood disturbance. There was no significant medical or surgical history. She was diagnosed as a case of Specific (isolated) phobia and managed with short term Benzodiazepine (Tab Alprazolam), graded exposure therapy, 
Cognitive Behavioural therapy and relaxation training leading to complete resolution of her symptoms and distress.

\section{Case 4}

A 28 years old female, a housewife and mother of two children was brought to ENT OPD by her husband with a history of foreign body sensation in the throat and hoarseness of 20 days duration. The lady gave a history of excessive gargling with hot saline water at home for the last 1 month. A videolaryngoscopy revealed diffuse laryngeal edema with extensive hyperemia of the endolarynx. There was edema of the arytenoids however the airway was adequate and the vocal folds were mobile. The patient was started on proton pump inhibitors and a short course of oral Prednisolone at $0.5 \mathrm{mg} / \mathrm{kg}$ for 1 week. She was also advised to stop gargling with hot saline water. There was mild relief in the symptoms but she confessed that she could not control the urge to gargle. In view of the above she was advised psychiatric consultation. History from the patient and her husband revealed that last month a family in their locality was tested positive for Coronavirus and their area was made a red zone and sealed. Gradually she developed recurrent thoughts that her throat was infected with the virus and she would start experiencing discomfort in her throat. It would lead to significant distress making her restless. Immediately she would do gargles with hot saline water leading to relief of her distress. However she would again have similar thoughts and would resort to similar act of gargling for temporary relief. After gargles she would have no such thoughts and feel robust. She would accept that this thought was her own and irrational however she had difficulty in resisting it. Over last 1 month her symptoms worsened significantly with escalation in frequency of gargling (40-50 times/day). She would experience severe anxiety if she tries to resist or unable to perform gargling due to any reason. She also developed sleep disturbance and poor self confidence to manage household chores. She was counselled several times by her husband but to no avail. Her clinical examination was normal. Mental state evaluation revealed obsessive thoughts of throat contamination with Corona virus and compulsive acts of saline hot water gargling. There was secondary anxiety in absence of any psychotic features in clear sensorium and disturbed biodrives. Psychometry revealed high YBOCS (32). Neuroimaging of the brain was normal. She was diagnosed and managed as a case of Obsessive Compulsive disorder with Tab Fluvoxamine $(50 \mathrm{mg})$ increased to $100 \mathrm{mg}$, short term Benzodiazepine (Tab Clonazepam), behaviour therapy, psychoeducation and relaxation training. Gradually she had improvement in symptoms with mitigation of her distress.

\section{Discussion}

The global catastrophe created by the COVID 19 pandemic can't be described by the available vocabulary. The evident and undisguised destruction to physical health caused by the pandemic needs no introduction but what is surprising is how it obscurely and inconspicuously started affecting the mental health of the population [8,9].The initial measures were completely dedicated to prevent the physical harm caused by the viral illness thereby completely neglecting the ill effects on the mental health and the psyche of both healthy and affected individuals [10-14]. Even the health care workers were not spared of the psychological effects of the COVID 19. All this led to emergence of 'novel' symptoms in seemingly healthy individuals and resurgence of latent symptoms in individuals with known mental health issues. Attributing ENT symptoms to COVID 19 is one such trend described in this case series.

In this case series we have discussed how this ongoing COVID 19 pandemic is making our way into our physical and mental world. This sudden shift of social dynamics and changing role pattern is promulgating a state of mental turmoil and distress manifesting in varied forms [3]. Flurry of emotions around are causing subtle damage to our psyche. It is the need of the hour to develop a holistic approach in a warm empathetic milieu to tackle this menace of COVID pandemic and provide effective psychiatric care for mental wellness. A good comprehensive history will serve as a helpful screening tool. Management in such cases first involves ruling out organicity. Patients must be handled with empathy, reassurance and positive feedback. Psychoeducation will help to allay undue worries and apprehensions along with cognitive distortions. Relaxation training, cognitive behaviour therapy along with use of psychotropics have proven beneficial for good recovery. Needless to say that this case series highlights only the tip of the iceberg and what lies beneath is still concealed to the human eyes.

\section{References}

1. Druss BG (2020) Addressing the COVID-19 pandemic in populations with serious mental illness. JAMA Psychiatry 77(9):977-978. https://doi.org/10.1001/jamapsychiatry.2020.1701

2. Wind TR, Rijkeboer M, Andersson G, Riper H (2020) The COVID-19 pandemic: the 'black swan' for mental health care 
and a turning point for e-health. Internet Interv 20:100317. https://doi.org/10.1016/j.invent.2020.100317

3. Ornell F, Schuch JB, Sordi AO, Kessler FHP (2020) "Pandemic fear" and COVID-19: mental health burden and strategies. Braz J Psychiatry 42:232-235

4. Wang C, Pan R, Wan X et al (2020) A longitudinal study on the mental health of general population during the COVID-19 epidemic in China. Brain Behav Immun 87:40-48. https://doi.org/ 10.1016/j.bbi.2020.04.028

5. Luykx JJ, Vinkers CH, Tijdink JK (2020) Psychiatry in times of the coronavirus disease 2019 (COVID-19) pandemic: an imperative for psychiatrists to act now. JAMA Psychiatry. https://doi.org/10.1001/jamapsychiatry.2020.1225

6. Hao F, Tan W, Jiang L et al (2020) Do psychiatric patients experience more psychiatric symptoms during COVID-19 pandemic and lockdown? A case-control study with service and research implications for immunopsychiatry. Brain Behav Immun 87:100-106. https://doi.org/10.1016/j.bbi.2020.04.069

7. Grover S, Dua D, Sahoo S, Mehra A, Nehra R, Chakrabarti S (2020) Why all COVID-19 Hospitals should have mental health professionals: the importance of mental health in a worldwide crisis!. Asian J Psychiatry 51:102147. https://doi.org/10.1016/ j.ajp.2020.102147

8. Pfefferbaum B, North CS (2020) Mental health and the Covid-19 pandemic. N Engl J Med 383(6):510-512. https://doi.org/ 10.1056/NEJMp2008017

9. Holmes EA, O'Connor RC, Perry VH et al (2020) Multidisciplinary research priorities for the COVID-19 pandemic: a call for action for mental health science. Lancet Psychiatry 7(6):547-560. https://doi.org/10.1016/S2215-0366(20)30168-1

10. Oliver N, Lepri B, Sterly H et al (2020) Mobile phone data for informing public health actions across the COVID-19 pandemic life cycle. American Association for the Advancement of Science, Washington

11. Wong J, Goh QY, Tan Z et al (2020) Preparing for a COVID-19 pandemic: a review of operating room outbreak response measures in a large tertiary hospital in Singapore. Can J Anesth Can Anesth 67(6):732-745. https://doi.org/10.1007/s12630-020-01 620-9

12. Khosravani H, Rajendram $P$, Notario L, Chapman MG, Menon BK (2020) Protected code stroke: hyperacute stroke management during the coronavirus disease 2019 (COVID-19) pandemic. Stroke 51:1891-1895

13. Cheng KK, Lam TH, Leung CC (2020) Wearing face masks in the community during the COVID-19 pandemic: altruism and solidarity. The Lancet. https://doi.org/10.1016/S0140-6736(20) 30918-1

14. Al-Shamsi HO, Alhazzani W, Alhuraiji A et al (2020) A practical approach to the management of cancer patients during the novel coronavirus disease 2019 (COVID-19) pandemic: an international collaborative group. Oncologist 25:e936

Publisher's Note Springer Nature remains neutral with regard to jurisdictional claims in published maps and institutional affiliations. 